\title{
Campaign Spending Limits, Incumbent Spending, and Election Outcomes
}

\author{
Kevin Milligan \\ Department of Economics \\ University of British Columbia \\ Marie Rekkas \\ Department of Economics \\ Simon Fraser University
}

November, 2007

\begin{abstract}
We study the impact of campaign spending limits for candidates in Canadian federal elections. We first demonstrate that spending limits are binding mostly for incumbent candidates. We then use this information to produce endogeneity-corrected estimates for the impact of incumbent spending on electoral vote shares. Furthermore, we examine the impact of spending limits on broader measures of electoral outcomes, finding that larger limits lead to less close elections, fewer candidates, and lower voter turnout.
\end{abstract}




\section{Introduction}

Campaign finance reform is a topic of heated public policy debate in the United States and Canada. Although concerns have long been raised about the advantage possessed by candidates with greater resources, this perception of unfairness has grown over time with the magnitude of election expenditures. For example, total campaign spending in the 2004 U.S. presidential race by the major party candidates measured in the hundreds of millions of dollars, more than double of that spent in the 2000 race. In Canada, the scale of federal election expenditures is smaller but nonetheless substantial, with total party and candidate campaign spending exceeding one hundred million Canadian dollars in the 2004 general election.

In an effort to enhance the fairness of the electoral process, Canadian governments have introduced a variety of campaign finance reforms. The presence of campaign spending limits, in particular, presents an opportunity for researchers to study the consequences of such policies. Understanding how spending limits as well as spending affect electoral outcomes is central to the discussion surrounding campaign finance regulation. In this paper, we use spending limits to evaluate the impact of candidate spending on voting outcomes. Moreover, we broaden the analysis to incorporate diverse democratic outcomes including voter turnout, the margin of victory, and the number of candidates. Our approach allows us to connect the impact of spending directly to the influence of spending limits, allowing a more complete analysis of the potential for policy to change electoral outcomes.

A recognized issue confronting researchers working in this area is the endogeneity of campaign spending. For instance, if a high quality candidate is able to raise and spend more funds, then this would lead to an upward biased OLS coefficient on spending from a regression of votes on spending. We estimate the impact of campaign spending on electoral outcomes 
through the use of an instrumental variables strategy based on particularities of the formula that determines the mandated spending limits for local campaigns in Canadian federal elections. Using the variation in campaign spending induced by the limit formula rather than the endogenous variation in campaign spending allows us to identify the effect of campaign spending on vote shares and other electoral outcome measures. Our identification approach represents a novel addition to the literature with arguable advantages over the existing strategies, to which we now turn.

The empirical investigation of campaign spending and electoral outcomes has been active for three decades (see Rekkas (2007), Erikson and Palfrey (2000, 1998), Gerber (1998), Levitt (1994), Nagler and Leighley (1992), Green and Krasno (1988), Jacobson (1978)). Researchers have employed a diverse set of instruments to confront this question, with sharply varying results. A common (although not universal) finding in research correcting for endogenous quality is that spending maps into greater vote share for challengers, but not for incumbents.

Perhaps the most clever identification strategy is by Levitt (1994). Levitt estimated the effect of campaign expenditures on vote share for House elections in the U.S. by restricting his sample to repeat challengers. He found that campaign spending had a small effect regardless of whether the candidate is a challenger or an incumbent. While a novel approach, this study may suffer from lack of generality—spending effects from repeat challengers may differ from other races. Further, for multiparty races experienced in Canada, this approach is not feasible as the set of repeat candidates over several election cycles would be extremely small, if not empty. ${ }^{1}$

${ }^{1}$ Evans (2007) uses data for Canadian federal elections from 1979 to 2000 and considers estimation with the repeat challenger districts. A total of 47 pairs of contests had the same majority and challenger candidates in successive elections. This figure would drop significantly if one considered multiparty (greater than two) repeat districts. 
Jacobson (1978) used the number of years the incumbent has served as well as an indicator for whether the challenger has held public office as instruments. However, it seems plausible that both of these factors could affect the candidate's vote share. This criticism has been noted in the literature (see for instance Welch (1981)). Green and Krasno (1988) used lagged incumbent spending as an instrument for current period incumbent expenditures, but if these lagged expenditures are correlated with unobservable incumbent quality then the exogeneity of the instrument may be compromised. Gerber (1998) used state population and candidate wealth as instruments. Yet, a large body of evidence suggests that state population should instead be included as an exogenous variable in the second stage regression. In light of all these concerns, Erikson and Palfrey (1998) argued that good instruments may simply not exist and instead took the different approach of simultaneous equation estimation with zero-covariance restrictions.

Given the exogeneity concerns levelled at previously-used instruments, we propose with this paper the use of the expenditure limit formula as an instrument. These limits are imposed by law and while we expect limits to have an effect through their impact on campaign spending, we do not expect limits to have any causally prior direct effect on any particular candidate's vote share. Beyond any logical claim to exogeneity, our specification tests also statistically validate our choice of instrument.

In addition to providing estimates of the effect of campaign spending that are arguably more credible, our paper has two additional contributions. First, we provide a detailed examination of the patterns of spending in Canadian general elections as well as a detailed look at how limits affect campaign spending. In order to properly think about policy regarding limits, it is crucial to understand their impact on campaign expenditures. And second, we extend the existing literature surrounding spending limits, for which only a limited amount of empirical work exists. 
Stratmann and Aparicio-Castillo (2006) show that the introduction of contribution limits at the state level increases the closeness of a race. A paper by Palda and Palda (1998) touches on limits by simulating the impact spending limits would have on French elections. Ours is the first paper to directly estimate the impact of spending limits on a variety of democratic outcomes.

We have several interesting findings. We find that—for the case of Canada in the elections we study—incumbent candidates are three times as likely as challengers to spend more than $90 \%$ of their allotted limit. For vote shares, we find that spending by incumbent candidates is productive, and that our endogeneity-corrected estimates are larger than the corresponding OLS estimates. Looking at broader electoral outcomes, we also find that observationally equivalent districts with higher spending limits feature lower electoral turnout, less close races, and fewer candidates running.

We begin the paper with a detailed analysis of how the campaign spending limit works in Canada, followed by a description of our dataset and background on the 1997 and 2000 elections, which are the focus for our estimation. Next, we discuss our empirical strategy, paying close attention to the sources of identification. Finally, we present the empirical results for the impact of the limit on spending and then for the electoral outcomes. We close with some concluding remarks.

\section{Election expenditure limits}

Policy on campaign finance has focused both on limiting contributions and on restricting expenditures. Since the 1974 amendments to the Federal Election Campaign Act that introduced contribution limits in the U.S., campaign finance reform has largely focussed on contribution limits. Currently, there exist legal limits on what individuals, political action committees, and 
state/local/national political parties can contribute. For presidential elections, there are also spending limits, although they can be avoided. ${ }^{2}$

In contrast, campaign finance reform in Canada has more heavily focused on regulating the amount of money spent during elections. ${ }^{3}$ While candidates in Canadian federal elections are not limited with respect to how much money they can raise, their expenditures are limited and governed by the Canada Elections Act. ${ }^{4}$ Section 407 of the Act defines election expenses broadly to include items from advertising and promotion to remuneration for campaign workers to surveys and research. These items are deemed expenses if the good or service was received, whether or not payment was made. Any surplus in revenue at the local level must be returned to the appropriate party (i.e. the chief agent of the party, the local association, etc.) as outlined in the Act. A candidate qualifies for reimbursement of $50 \%$ of his election expenses provided the candidate receives at least $15 \%$ of the valid votes cast in his electoral district. Election expenditures made by a registered party as part of the national campaign are governed by a separate section of the Act and are not our focus here.

Given the focus of the paper is on expenditure limits in Canada and given that we exploit several details of the expenditure limit formula in our empirical strategy, we provide in the rest of this section a detailed description of how the Canadian formula works.

The amount of the limit per candidate is determined by a formula, provided in section 441 of the Act. The input to the formula consists of two numbers: the number of electors and the area in square kilometers of each federal electoral district (FED). The number of electors is determined

\footnotetext{
${ }^{2}$ In the 1976 Supreme Court case Buckley v. Valeo, spending limits were ruled unconstitutional. See Levitt (1994) for more discussion of spending limit policy in the US. In the 2004 presidential election, both President Bush and Senator Kerry opted not to receive public funding during the primaries and therefore were not bound by the primary spending limit of about $\$ 45$ million.

${ }^{3}$ Recent reforms have extended regulations to control campaign contributions.

${ }^{4}$ The current Canada Elections Act came into force on September 1, 2000. The candidate election expense provisions of the previous Canada Elections Act were identical.
} 
first by the preliminary list of electors available at the start of the election. It is then updated with the final list of electors later in the campaign period. The final limit is the higher of the limit using the preliminary number and the final number. ${ }^{5}$ The area in square kilometers is available for each FED and does not change from election to election unless a new Representation Order comes into effect. ${ }^{6}$

These two numbers are combined through a complicated formula. The building blocks of the formula are a base amount related to the number of electors and a bonus for FEDs with low population density. For the number of electors, districts with a below-median number of electors instead use a 'modified' number of electors, which is the simple average of the actual number of electors in that FED and the Canada-wide median number of electors.

The base amount consists of a piece-wise linear function of the modified number of electors. Under the Act, \$2.07 is awarded for the first 15,000 electors. For electors over 15,000 and under 25,000, an additional $\$ 1.04$ per elector is awarded. Finally, for each elector over 25,000 an additional $\$ 0.52$ is awarded. The amounts are adjusted each year by an inflation factor. ${ }^{7}$

The bonus is awarded to districts that have a density of electors per square kilometer less than 10 . The bonus consists of the lower of two numbers: $25 \%$ of the base amount or 31 cents for every square kilometer in the FED. The equation for the limit therefore looks like this:

$$
\text { Limit }=f(\text { Modified Electors })+\text { Bonus , }
$$

where the function $f$ is defined as

\footnotetext{
${ }^{5}$ The 1997 election was the last for which a dedicated enumeration of electors was conducted during the campaign period. The 2000 election saw the first use of the permanent list of electors, which is maintained by Elections Canada and updated using various administrative sources of data between campaign periods.

${ }^{6}$ For the time period covered by our study, the 1996 Representation Order is in effect. Under the 1996 Representation Order, there are 301 FEDs.

${ }^{7}$ In 1997, the amounts were 2.02, 1.01, and 0.51 and in 2000 they were $2.11,1.06$, and 0.53 .
} 


$$
\begin{aligned}
f(M E)= & \$ 2.07 \times \min (15000, M E)+\$ 1.04 \times \min (10000, \max (0, M E-15000))+ \\
& \$ 0.52 \times \max (0, M E-25000)
\end{aligned}
$$

and the bonus is defined as

$$
\text { Bonus }=\min (0.25 \times f(M E), 0.31 \times \text { Area }) .
$$

In Figure 1 we graph the density of the limits for the 1997 and 2000 elections, as provided to us by Elections Canada. ${ }^{8}$ We transform the dollar values for both years to 2000 dollars. Almost all districts are in the range between $\$ 50,000$ and $\$ 80,000 .{ }^{9}$ Within this range, however, there is substantial variation.

To better understand the determinants of this variation, we plot two graphs that explore how the limit varies with the components of the formula. In both of these graphs we separate the data points into three groups: those with no bonus, those with the 'full' bonus of $25 \%$ of the base amount, and those with a 'partial' bonus based on district area. The unit of observations in these plots is the FED, with separate data points for 1997 and 2000.

First, in Figure 2, we show a scatter plot of the limit against the log of the number of electors in the district. The graph shows a clear positive relationship, owing to the linear components of the formula. Of note is the vertical distance between the three sets of FEDs. For the same number of electors, an FED could have one of three different limits based on the type of bonus it receives. This will prove helpful for our empirical strategy because it means that the limit is not solely a function of the number of electors, so the limit may have explanatory power even with rich controls for the number of electors.

The next graph in Figure 3 explores the source of the bonus. Because the bonus is awarded according to whether or not elector density is less than 10 , we place a line in the graph at 2.303 ,

\footnotetext{
${ }^{8}$ We describe our data sources in more detail in the next section.

${ }^{9}$ To be precise, the $1^{\text {st }}$ percentile is $\$ 52,612$ and the $99^{\text {th }}$ is $\$ 81,296$. The standard deviation is $\$ 5,377$.
} 
which is the natural $\log$ of 10 . The limit varies in interesting ways among the three groups of FEDs. First are the FEDs that receive the full 25\% bonus. Within this group, as elector density increases the limit tends to increase because a higher number of electors leads to a higher base and bonus. In the second set of points with a partial bonus, the limit heads down with higher density because the bonus is based on FED area. By the time density approaches 10, the magnitude of this bonus is diminished as the area becomes smaller. ${ }^{10}$ Finally, in the third set of points with no bonus the limit varies greatly with respect to elector density because the limit in this range depends only on the number of electors. Again, this figure displays the complexity of the interactions of the formula components.

To summarize, the campaign spending limit formula takes only two arguments, but combines them in complicated non-linear ways. This has the benefit of producing variation in campaign spending that may be empirically useful for understanding the effects of the limits on spending, and ultimately, on other election outcomes as well.

\section{Data}

We draw on the Canadian elections of 1997 and 2000 to form our dataset. ${ }^{11}$ During these elections, the following main parties accounted for approximately $98 \%$ of the total votes: the Liberal party (Liberals), the Reform party (Ref), the Canadian Reform Conservative Alliance party (CA), the Progressive Conservative party (PC), the New Democratic Party (NDP), and the

\footnotetext{
${ }^{10}$ For example, the Dewdney-Alouette riding in British Columbia under the 1996 Representation Order had an area of $6972 \mathrm{~km}$. Its elector density of 9.88 in 1997, being under 10.0, qualified it (by our calculations) for a bonus of $\$ 2,161$ based on area.

${ }^{11}$ In the Canadian electoral system, Members of Parliament are elected by simple plurality: a seat in the House of Commons is won by the candidate who obtains the most votes in an electoral district or riding. In contrast to American Members of Congress, Members of Parliament have considerably less freedom in their legislative conduct because the nature of confidence votes compels them to vote along party lines. There is therefore less incentive for candidates to accept money/contributions in exchange for favours that deviate from their party platform. This may explain the relatively small amounts spent in these election races.
} 
Bloc Québécois party (BQ). All other parties (e.g. Green Party, Marijuana Party, MarxistLeninist Party) and independents we classify under the "fringe" umbrella, as they tend to attract a very small share of votes and very infrequently elect a candidate. In terms of the political ideological spectrum, the PC, Reform, and CA parties are the right-of-centre parties. The Liberal Party straddles the centre, while the NDP is left-of-centre. The BQ is foremost a Quebec sovereigntist party, but tends ideologically to the left.

The 1997 Canadian federal election took place on June 2, 1997. A total of 1,672 candidates ran, spanning 301 electoral districts. All districts had a minimum of three candidates, while 212 districts had five or more candidates. The Liberal, PC, and NDP parties ran candidates in all 301 ridings, the Reform party ran 227 candidates, and the Bloc ran candidates in all 75 ridings in Quebec. Although the Liberal Party received only 38.5\% of popular vote, it achieved a majority government with 155 of the 301 seats. The Reform Party formed the official opposition with 60 seats, and the remaining 86 seats were split among the Bloc, NDP, PC parties (along with one independent). Overall, $70.1 \%$ of districts were won by incumbent candidates.

The 2000 Canadian general election was held on November 22, 2000. A total of 1,808 candidates ran, spanning the same 301 districts. All districts had a minimum of three candidates and 238 districts had five or more candidates. The Liberal party ran a candidate in all 301 ridings, while the PC party ran 291 candidates, the NDP and Canadian Alliance parties ran 298 candidates each, and the Bloc ran 75 candidates. Again the Liberal party secured a majority government with 172 seats and $40.8 \%$ of the popular vote. The Canadian Alliance formed the official opposition with 66 seats, and the remaining 63 seats were split among the Bloc, NDP and PC parties. Incumbents won $83.7 \%$ of the ridings. The election period for both elections was 36 days. 
To construct our dataset we use three sources: election outcomes, census data, and spending data. The data from these three sources are merged to form a dataset at the candidate level for 1997 and 2000, and also a dataset at the FED level for each of the years. Below we describe the three components of our dataset in more detail.

We begin with a dataset of election results originating from the Library of Parliament. This data, described in Milligan and Smart (2006), provides candidate-level information on party affiliation, number of votes, incumbency status, and candidate experience and education. From this information we form the following variables for our analysis: the margin of votes between the winner and the second-place candidate, the candidate's vote share, and voter turnout. To control for candidate quality, we include three measures of candidate experience and one measure of education. ${ }^{12}$ The experience variables we use are binary variables that take on the value one if: the candidate is or was a Member of Parliament, the candidate has provincial experience (member of provincial parliament, minister, party leader, premier, lieutenant governor), the candidate has municipal experience (mayor, council, school board). The education variable we use is also a binary variable that takes on the value one if the candidate has a university degree or is a member of the Privy Council.

To the election outcomes we merge data from the 1996 Canadian Census. The census data is available at the level of the FED. Most of the information relates to the status of Canadians on census day on May $14^{\text {th }}, 1996$. However, some income and labour supply measures relate to values from the calendar year of 1995 . We attach these same 1996 census variables to both the

\footnotetext{
${ }^{12}$ We thank Michael Smart for providing this data. The candidate experience and education data originating from the Library of Parliament are available only for past and present Members of Parliament. Among incumbents, 520 have previously been an MP and among challengers, 188 had previously been an MP. Thus while our included measures of candidate quality may be limited, they nonetheless represent a significant improvement to the literature as studies addressing campaign spending for Canada have not controlled for candidate quality. Challenger quality measures have been used in U.S. election studies by for example, Green and Krasno (1988), Krasno and Green (1988), and Bond et al. (1985).
} 
1997 and 2000 election results by FED. ${ }^{13}$ The control variables we create include the age structure of the population, the sectors of employment, education, share who rent accommodations, and the share of immigrants. ${ }^{14}$

Finally, we merge in data which originates from Elections Canada. These data include the amount spent on the campaign by each candidate, the final number of electors, and the campaign spending limit. The campaign spending variable represents the total amount of expenses incurred by candidates during the campaign period and includes such items as: advertising (radio, television and other), salaries, office expenses (rent and other), and other general miscellaneous expenses. This measure does not include national party campaign spending. Advertising expenses spent on items other than radio and television, such as money spent on flyers and signs, accounted for the largest share of total candidate expenses. The final number of electors and the campaign spending limit are reported at the level of the FED for each year, as they do not vary by candidate. ${ }^{15}$

While our available data span two elections, we will not be exploiting the panel structure in our analysis as there is very little within FED variation in the limit across these elections. Given the variation that we exploit is largely cross-sectional, we are careful to include rich controls for characteristics that vary across districts.

\footnotetext{
${ }^{13}$ One could consider attaching the 2001 Census variables to the 2000 FEDs, as the year is closer to the target. However, we prefer to use the 1996 census variables because the explanatory variables recorded after the election could be influenced by the results of the election, introducing an unwanted endogeneity.

${ }^{14}$ For age, we include the proportion in the following age groups: $15-44,45-64,65$ plus. The proportion $0-14$ is the excluded category. For sectors of employment, we use three categories: goods, services, and primary. Services is the excluded category. For education, we include the share with highest level of education less than high school, high school graduates, and some post-secondary. The share with a university degree is the excluded category.

${ }^{15}$ We attempted to generate the provided limits given the district area and the final number of electors. In all cases, our estimated limit exceeded the limit provided by Elections Canada. The resolution to this difference may lie in the fact that the final limit is the greater of the limit based on the preliminary list of voters and the final list of voters. In our empirical work in this paper we rely on the final list of voters and the limit provided by Elections Canada.
} 


\section{Empirical Strategy}

Our dataset consists of two cross-sections of candidate and FED level data. We use these data to address two related questions. First, we look at the impact of the mandated limit on campaign spending. Second, we estimate how spending and the spending limit influence election outcomes.

If one were interested in explaining the determinants of spending in the presence of a spending limit, the correct approach might employ Tobit estimation to account for the limited dependent variable. However, as we are ultimately interested in the effect of spending on electoral outcomes, we instead use the limit as an instrument to predict spending. That is, we use the variation in spending induced by the variation in limits across districts to estimate the causal impact of spending on outcomes using an instrumental variables approach.

As was made clear in Section II, the limit formula depends critically on both the number of electors and the density of population in each FED. An important concern is the source of the variation in the limit—if identification comes from the exclusion of non-linear terms in the formula components and if those non-linear terms are determinants of election outcomes, then the exclusion would be invalid. However, as we demonstrate below, identification comes from interactions of the formula components and in sharp discontinuities in the 'bonus' schedule of the formula.

Recalling the discussion of Figure 2, districts with the same number of electors receive different limits due to the bonus given to lower density districts. In this way, the formula depends on the interaction of the two components. It seems reasonable to expect that electoral outcomes may depend on some unspecified function of the number of electors or the density of electors. For this reason, we control for a polynomial in each of these components. However, it is harder 
to conceive of a theoretical justification for including the interaction of the formula components. It is this set of interactions that, when excluded, contributes to our identification.

The other aspect of identification can be seen in Figure 3. The size of the bonus received depends on which side of the threshold of 10 electors per square kilometer the riding falls. This discontinuity can be exploited for identification so long as there are no highly non-linear influences of elector density on our electoral outcomes. Again, in our specification we will control for a polynomial in elector density to account for any direct impact of density on electoral outcomes.

To further investigate the importance of these different factors to identification, we ran regressions trying to explain the limit variable, using one observation per district. When we use as explanatory variables a quartic polynomial in the number of electors and another quartic in elector density, the R-squared is 0.503 . This leaves substantial variation in the limit that may potentially be used for identification. To gain a deeper understanding of this remaining variation, we added more regressors. Including the interaction of these two sets of quartic terms with each other raises the R-squared to 0.562 . Adding a dummy variable for each of the three ranges for the “low density” bonus raises the R-squared to 0.870. Finally, adding interactions of the bonus dummies with each of the quartic terms leads to an R-squared of 0.981 . These regressions have two important implications. First, the high R-squared on the last of these regressions demonstrates that we understand well the source of the variation in limits. Second, almost half the variation in the limit can be explained by interactions between terms and the bonus (which depends on interactions between terms). We argue that these interactions may plausibly be excluded from the second stage. In addition to these logical arguments for identification, we submit our instrumental variables strategy to standard specification tests. 
Even if using the limit successfully purges any endogenous response of spending to candidate quality, our identification may still be threatened if candidates base their decision to run on the size of the limit in their riding — high quality challengers may be afraid to run if incumbents can spend a lot. We address this to some extent through including our measures of candidate quality, including the empirically important control for past parliamentary experience.

The first-stage estimation equation takes the following form:

$$
\text { spending }_{j r t}=\beta_{0}+\beta_{1} \text { limit }_{r t}+\beta_{2} \text { electors }_{r t}+\beta_{3} \text { density }_{r t}+\beta_{4} x_{j t}+\beta_{5} x_{t}+\beta_{6} x_{r}+\varepsilon_{j r t} \text {, }
$$

where $j$ denotes the candidate, $r$ the electoral district and $t$ the year of the election. The dependent variable spending $g_{j t}$ reflects candidate $j$ 's campaign spending in district $r$ in year $t$. The variable limit $_{r t}$ represents the campaign spending limit in riding $r$ in year $t$, electors $s_{r t}$ represents a quartic polynomial in the number of electors in riding $r$ in year $t$, and density $y_{r t}$ represents a quartic polynomial in the population per square kilometer (population density) in riding $r$ in year $t .^{16}$ The remaining covariates in the model, $x_{j t}, x_{t}$, and $x_{r}$ are variables that capture candidate-year, year, and riding specific variation, respectively. The candidate-year term is a vector of variables that reflects candidate attributes including party affiliation and incumbency status. This vector also includes controls for candidate quality, in particular, three measures of candidate experience as well as a measure of candidate education. The year term reflects a year fixed effect included in the model to absorb unobservables specific to a given election. The riding-specific term is a vector of variables that contains census controls. These variables will be discussed further in the next section. The stochastic error term is denoted as $\varepsilon_{j r t}$.

\footnotetext{
${ }^{16}$ We tried including the formula components as linear, quadratic, quartic, and eigth-order polynomials. The results were not very sensitive to the richness of the controls.
} 


\section{Campaign spending and limits}

In this section we present our results on campaign spending and limits. First, we show descriptive statistics on campaign spending. We then present and discuss regression results examining the question of how the limits affect observed campaign spending.

\section{Descriptive statistics on campaign spending}

Table 1 records the moments from the distribution of campaign spending for different subsamples of the data. Dollar values have been adjusted to constant year 2000 dollars. The average spending across all candidates and years was $\$ 22,807$ per candidate with a standard deviation of \$23,788. Despite fewer candidates running in the 1997 election, average expenditures were higher at $\$ 24,713$ compared to $\$ 21,044$ for the 2000 election. This difference is largely due to the Reform/CA party candidates. ${ }^{17}$

The distribution of candidate campaign expenditures appears in Figure 4. From this figure it is immediately clear that a large number of candidates have expenditures very close to zero. This aspect can also be gleaned from the first three rows of Table 1 where it is evident that $10 \%$ of candidates report expenditures of zero and 25\% of candidates spend $\$ 731$ or less (across both elections). Figure 4 also shows another bulge of expenditures peaking around \$60,000.

A summary of election expenditures incurred by the five major parties is also provided in Table 1 . The BQ party candidates spent the most, averaging $\$ 54,486$ per candidate, followed by the Liberal party candidates, averaging \$48,761 per candidate. It is not surprising that the BQ candidates spent more than the Liberal candidates as the BQ party fields only 75 candidates and

\footnotetext{
${ }^{17}$ In 1997 the Reform party ran 227 candidates, while in 2000 the Canadian Alliance ran 298 candidates. Sixtythree of these 71 additional candidates were fielded in Quebec as a strategic response to criticism that the Reform party was not sufficiently national in scope. These candidates were not competitive in Quebec and spent relatively little there.
} 
focuses on a geographically concentrated portion of the electorate. The Reform/CA party candidates spent an average of $\$ 31,775$ per candidate, followed by the PC candidates which spend $\$ 23,487$ on average. Of the major party candidates, the NDP spent the least, an average of $\$ 15,942$ per candidate. The New Democratic Party relies more heavily on volunteer labour than do other parties, and since nonremunerative expenses are not included in the expenditure variable, this outcome is not surprising. The fringe party candidates spent the absolute least, averaging \$1,685 per candidate. This mean is misleading as there were a few notable independent candidates who spent a large amount. Thus the median of $\$ 187$ is more reflective of the expenditures of the fringe party candidates.

Table 1 also reveals that more on average is spent in rural districts (those with population density below the median) than in urban districts (those with population density above the median). This may reflect the reality that it is more costly to campaign in districts that are physically large, where door-to-door campaigning and the dissemination of promotional materials is more costly.

As expected, incumbents spend more on average than challengers, with averages of $\$ 52,520$ and $\$ 17,516$ respectively. Further, approximately a third of incumbent candidates spend more than $90 \%$ of their limit, compared to less than $11 \%$ of all candidates. ${ }^{18}$ Similarly, winners spend more than losers, with averages of $\$ 52,774$ and $\$ 16,538$ respectively. The differences are stark at the lower percentiles.

\footnotetext{
${ }^{18}$ We use this 90 percent threshold solely for exposition; it does not play a role in our estimation strategy. One might consider being at 90 percent of the limit as being 'effectively' constrained, since there are strong penalties for exceeding the limit and much uncertainty in the course of a campaign. In a recent anecdote, a campaign manager in the 2006 federal election budgeted at 88 percent of the allotted limit for precisely this reason (The Province (2007)).
} 


\section{Regression results}

Table 2 contains our regression results for the effect of limits on campaign expenditures. The dependent variable is candidate expenditures (in thousands of year 2000 dollars) in all cases. The key coefficient for the regressions in this table is the campaign spending limit scaled in thousands of year 2000 dollars. Two sets of covariates are considered: with formula controls, and adding census and political controls. We also consider two subsamples of the data: just major parties and just incumbents.

The base specification (a) includes province and year fixed effects as well as quartic polynomials for population density and the number of electors. Using the full candidate dataset, the estimated impact of increasing the limit by $\$ 1$ is an insignificant $\$ 0.04$ in spending. The second specification adds riding-level controls from the Census data as well as riding and candidate-level political controls. These additional covariates in column (b) vastly increase the explanatory power of the model as measured by the R-squared, which jumps to 0.651 . However, the estimated impact of the limit stays in the same range and remains statistically insignificant.

The other control variables appearing in column (b) contain some interesting results, as well. Candidates with prior experience, at the federal level (through being a past Member of Parliament) or at the provincial level, spend more compared to candidates without this experience. Incumbents, however, spend \$2,860 less than non-incumbents. This overturns the huge expenditure advantage for incumbents observed in the raw means in Table 1 . This suggests that most of the incumbent spending advantage comes through being a past MP rather than being a pure incumbency effect. ${ }^{19}$ Interestingly, candidates with municipal experience are found to spend less than candidates without this type of experience. Candidates who possess a degree or

\footnotetext{
${ }^{19}$ These can be separately identified because some ridings feature past MPs who are not incumbents.
} 
were members of the Privy Council did not have different spending patterns compared to those candidates without this education. For the political party controls, the dummies show that, relative to the excluded Liberal Party candidates, only the Bloc candidates spent on average more. NDP and fringe candidates spent sharply less than Liberal candidates.

In the continuation of Table 2 are the census variable results. Spending appears to be increasing in the average income of the district, but decreasing in the share of employment in primary industries. The next set of results running down column (b) shows the impact of electoral district education and age share results. A higher share of the population with only primary education leads to more spending, while greater 15-44 and 65 plus age shares also predict higher spending. The share of renters and immigrants has no significant impact.

In column (c), we restrict the sample to include only major party candidates. The descriptive statistics in Table 1 suggest that spending for fringe candidates is very unlikely to be influenced by the limit, so excluding fringe candidates could change the result by focusing on candidates more likely to be affected by the limit. However, the results in column (c) for the limit variable are not much changed from the previous columns.

Finally, in column (d), we restrict the sample to include only incumbent candidates for the same reason as in column (c)—-to see if results differ among a likely-to-be-constrained subsample. Here, we find a large and statistically significant impact of the formula on spending. For an extra $\$ 1$ of expenditure limit, incumbent candidates on average will spend an extra $\$ 0.42$.

Taken together, these results suggest that variation in the spending limit across electoral districts has a large impact on the spending behaviour of incumbent candidates, but next to no impact on other candidates' spending. This difference across incumbent and non-incumbent candidates will be exploited further in our instrumental variables results in the next section. 


\section{The impact of spending on electoral outcomes}

Before embarking on a discussion of the regression results on electoral outcomes, a preliminary visual examination of our empirical strategy is found in Figure 5. We have graphed candidate vote shares for incumbents against the spending limit for their districts and fitted a simple regression line. This shows the 'reduced form' relationship between our instrument (the limit) and the dependent variable of interest (vote shares). The slope of the bivariate relationship is positive with a magnitude of 0.35 , suggesting a relationship between limits and eventual election outcomes. Of course, other factors varying across big and small limit districts may underlie this correlation. In the regressions discussed below we include control variables to tighten the causal inference.

There are two sets of results. The first set uses a candidate-level dataset to examine the impact of higher campaign spending by a candidate on his or her vote share. The second set of results looks at broader measures of electoral outcomes at the riding level.

\section{Spending and Vote Shares}

We begin with an analysis of the effect of campaign spending on vote shares. To address the endogeneity concerns described in the Introduction, we exploit the impact of the limit on spending using the findings from Section V. That is, we use the variation in campaign spending induced by the limit formula rather than the full and potentially endogenous variation in campaign spending.

We do this using an instrumental variables approach with a first stage consisting of a candidate's campaign spending regressed on our control variables and two instruments. The instruments we use are the limit for that electoral district and the interaction of the limit with 
incumbency status. This interaction allows the limit to have a different impact for incumbents and non-incumbents. It is important to note that we still include the main effect of incumbency status as a control variable in both stages.

The identification assumption remains similar to that discussed earlier in Section IV. That is, we assume that the interactions of elector density with the number of electors can reasonably be excluded from the $2^{\text {nd }}$ stage regressions. By including the interaction with incumbency status, identification additionally requires that this exclusion is also valid for incumbents; that there is no explanatory power of density-electors interactions for incumbents. ${ }^{20}$

The results from the regressions are reported in Table 3. Each column represents a different regression, with the first stage coefficients reported in the upper panel and the second stage coefficients in the lower panel. We report only the key coefficients of interest.

The first column displays the OLS results. The impact of an extra \$1,000 in campaign spending is an extra 0.34 in vote share. Taking the standard deviation of incumbent spending $(\$ 11,342)$, this implies a large 3.9 percentage point increase for a one standard deviation change in spending. The coefficient on incumbents is also reported, indicating an advantage of 8.24 percentage points of vote share for incumbency. Of course, these estimates are potentially biased by the endogeneity problems discussed above. We therefore turn to our IV estimates.

Column (b) of Table 3 shows the results using the campaign spending limit as an instrument for spending. The first stage results in the top panel of the Table show that the impact of the limit

\footnotetext{
${ }^{20}$ In the literature, opponents' spending sometimes appears as an explanatory variable for vote shares. Like a candidate's own spending, this variable is endogenous. As Table 2 makes clear, our instrument is effective only for predicting incumbent spending, so our instrumental variable strategy would not be appropriate for predicting opponents' spending. We have tried including an opponents' spending variable in regressions otherwise similar to those appearing in Table 3 and have found that the results for our variables of interest are similar. Another variable that often appears on the right-hand side of the vote-share equation is the margin of victory, in order to reflect the competitiveness of the race. However, we regard the competitiveness of the race as one of the outcomes of a change in the spending limit regime, so we do not include it in our models presented here. In vote-share regressions that do include the margin of victory, we find little impact on the results for our variables of interest.
} 
on spending is insignificantly estimated at only $\$ 0.07$. The resulting $2^{\text {nd }}$ stage estimate is uninformative given its imprecision.

The problem with this specification is that the limit does not affect all candidates equally. In Table 2, we demonstrated that the limit has a much greater impact on incumbents than other candidates. We therefore try interacting the limit variable with the indicator for incumbency, which allows the effect of the limit to be different for incumbent and non-incumbent candidates. It is important to note that the dummy for incumbency remains as a control variable in both stages of the estimation - it is only the interaction of incumbency with the limit and the limit itself which are excluded from the $2^{\text {nd }}$ stage.

The results from this IV estimation are presented in column (c) of the Table. In the first stage, the effect of the limit on non-incumbents can be determined by the coefficient on the limit variable. The estimate is small and insignificantly different from zero. However, the coefficient on the interaction term between incumbency and the limit results in a strongly significant $\$ 0.61$ differential increase in spending by incumbents for an extra $\$ 1$ of limit. Taking these two estimates together, they suggest an increase in $\$ 0.58$ for incumbent candidates for a $\$ 1$ increase in the limit. The $F$-statistic and $J$-statistic indicate strong statistical confidence in the exclusion of these instruments from the $2^{\text {nd }}$ stage of the estimation.

Our endogeneity-corrected estimate for the impact of campaign spending on vote shares is 0.77 , meaning that an extra $\$ 1,000$ of spending results in an increase of 0.77 in the vote share. Of interest, the IV coefficient in column (c) exceeds the OLS coefficient in the first column. Because our identification relies on the spending of incumbents who are close to the limit, this result is likely driven by the incumbent candidates in the sample. We pursue this further in the next table. 
In Table 4, we investigate the differences between incumbent and challenger spending. The first two columns display the OLS results of campaign expenses on vote share for subsamples of challenger and incumbent candidates, respectively. The OLS coefficient for challengers shows a large 0.35 response in vote share per $\$ 1,000$ of spending. In contrast, the coefficient for incumbents is small and insignificant.

The second two columns show our IV results, using just the limit variable as an instrument. ${ }^{21}$ For the challengers, the first stage coefficient on the limit is close to zero, suggesting little predictive power. Not surprisingly, the standard error on the second stage coefficient is too large to allow any inferences. For the incumbents, the first stage has strong predictive power, and the second stage shows a strong point estimate of 0.88 per $\$ 1,000$ of spending, although the standard error renders this significant only at the 10 percent level. This 0.88 coefficient lies within the 95 percent confidence interval around the 0.77 coefficient in column (c) of Table $3 .^{22}$ These results strongly suggest that it is the incumbent candidates that are driving the results we see in the pooled incumbent-challenger sample in Table 3.

The IV estimate for the vote share impact of extra spending is larger than the OLS estimate, and this finding is driven by the incumbent candidates. Jacobson (2006) suggests that more spending by incumbents may be correlated with an unobservably weak candidacy, which would tend to bias down the OLS coefficient. Our result therefore, is consistent with Jacobson’s suggestion. By correcting for the endogeneity of incumbent spending, a much stronger impact of incumbent spending emerges in our data set than has been found in previous research.

\footnotetext{
${ }^{21}$ The interaction term isn't possible with these subsamples, since everyone in the subsample is either challenger or incumbent.

${ }^{22}$ As a further test, we tried a regression using only incumbents spending 90 percent or more of the limit (a group which is effectively constrained by the limit). We find an extremely strong first stage leading to an estimate of 0.62 in the second stage with a standard error of 0.23 - again within the 95 percent confidence interval of our main estimate.
} 


\section{District Electoral Outcomes}

In order to address how changes to the spending limit affect electoral district level outcomes, we collapse our dataset to the election-district level, leaving us with 602 observations (2 elections for each of the 301 ridings). In these regressions, we use the same set of province dummies, year dummies, limit formula controls, and census characteristics as we did for the candidate level regressions. However, we do not include the candidate level political characteristics such as incumbency or party affiliation. The primary variable of interest in the regressions is the coefficient on the expenditure limit (measured in thousands of year 2000 dollars). An advantage of using several outcome variables is the ability to check that the findings are consistent with each other; that one result is not simply spurious.

In Table 5 we present the district-level results. Across the table are separate regressions using four different dependent variables. In all cases, it should be kept in mind that the channel through which the limits lead to the observed results is through the increase in incumbent spending noted in the previous results.

The first column looks at the margin of victory, measured in percentage points from 0 to 100 . An extra $\$ 1,000$ in contribution limit is estimated to increase the margin of victory by 0.831 of a point. A one standard deviation increase in the limit $(\$ 5,377)$ therefore implies a 4.5 point increase in the margin, which is $20.1 \%$ of the mean margin of victory. The result is strongly statistically significant.

In column (b) of Table 5, we examine voter turnout, measured as voters as a percent of electors. Here, an extra $\$ 1,000$ of limit results in voter turnout that is 0.266 points lower, or 1.73 points for a one standard deviation shift. This represents $4.2 \%$ of the mean turnout. If campaign spending provides information about campaign issues directly to voters, then voters will be more 
likely to turn out when they have more information (Feddersen and Pesendorfer (1996)). This may suggest that the extra spending by incumbents does not directly provide information about the candidates' positions.

The third column looks at the number of candidates running in the election. If larger limits induce fewer candidates to run because marginal candidates fear the spending power of other candidates, then we would expect larger limits to decrease the number of candidates. ${ }^{23}$ For contribution limits in the U.S. this hypothesis is supported by Stratmann and Aparicio-Castillo (2006) who find that a reduction in the individual donor contribution limit increases the number of candidates. The estimated impact is statistically significant at the 5 percent level, but the magnitude of -0.046 per $\$ 1,000$ of limit is very small.

Finally, column (d) estimates an OLS / linear probability model using as a dependent variable an indicator for whether the incumbent candidate won the election in that riding. The estimated impact of a limit expansion is a 0.003 increase in probability, which is statistically significant, but in magnitude of no practical importance.

These results are best interpreted together with the vote share results in Table 3 and Table 4 . Those findings suggest that increasing the limit leads to more spending by incumbents, followed by higher vote shares for the incumbents. Since incumbents won 70.1\% of ridings in 1997 and $83.4 \%$ in 2000 , this may explain why the margin of victory increases when the limit increases. The voter turnout result then follows directly. A standard finding in the literature is that turnout is positively correlated to the closeness of a race (see for example Cox and Munger (1989) and the references therein). If spending limits increase and incumbents receive further advantage, then the race may be perceived as less close, the expected margin of victory increases, and

\footnotetext{
${ }^{23}$ Palda and Palda (1985, p. 313) cites an Elections Canada document from the 1970s that motivates the campaign spending limitation on precisely this ground: Limits "ensure that any Canadian can consider becoming a candidate without fear of being overwhelmed by a more wealthy opponent.”
} 
therefore turnout falls. We turn finally to the probability of incumbent victory. Our estimate suggests that there is a negligible impact on this probability from increasing the campaign spending limit. Combined with the other results, the picture that emerges is that increases in campaign spending limits allow incumbents to spend more and increase their margin of victory-but without much impact on the electoral outcome. By 'running up the score', a more comfortable reelection is provided for incumbents.

\section{Conclusions}

In this paper, we use Canadian campaign spending limits to study the effectiveness of campaign spending and its impact on broader electoral outcomes. We find that the campaign limits were binding mostly for incumbent candidates. Higher spending is found to lead to greater vote share, with an endogeneity-corrected estimate higher than the OLS estimate. This may suggest that unobservably lower quality incumbents spend more to compensate for their shortcomings. We also find that higher spending limits lead to less close races, less voter turnout, and fewer candidates running. However, the probability for incumbent reelection is almost unchanged.

While our results make some advance on the empirical literature, they do not allow us to make broader welfare judgments. Since we uncover little impact of the limits on probabilities of reelection, it might be tempting to conclude that the real impact of the spending limits is minimal. However, if we consider the welfare of voters rather than candidates, then our results suggest that spending limits can have an impact on voters' welfare-if broader outcomes such as electoral participation through voter turnout and more candidates running are held to be important by citizens. 


\section{References}

Bond, J.R., Covington, C., Fleisher, R., 1985. Explaining Challenger Quality in Congressional Elections. Journal of Politics 47,510-529.

Cox, G.W., Munger, M.C., 1989. Closeness, Expenditures, and Turnout in the 1982 U.S. House Elections. The American Political Science Review 83(1), 217-231.

Erikson, R.S., Palfrey, T.R., 1998. Campaign Spending and Incumbency: An Alternative Simultaneous Equations Approach. Journal of Politics 60(2), 355-373.

Erikson, R.S., Palfrey, T.R., 2000. Equilibria in Campaign Spending Games: Theory and Data. American Political Science Review 94(3), 595-609.

Evans, T.A., 2007. An Empirical Test of why Incumbents Adopt Campaign Spending Limits. Public Choice 132, 437-456.

Feddersen, T., Pesendorfer W., 1996. The Swing Voter’s Curse. American Economic Review 86(3), 408-424.

Gerber, A., 1998. Estimating the Effect of Campaign Spending on Election Outcomes Using Instrumental Variables. American Political Science Review 92(2), 401-411.

Green, D.P., Krasno, J.S., 1988. Salvation for the Spendthrift Incumbent: Re-estimating the Effects of Campaign Spending in House Elections. American Journal of Political Science 32(4), 884-907.

Jacobson, G.C., 1978. The Effects of Campaign Spending in Congressional Elections. American Political Science Review 72 (2), 469-491.

Jacobson, G.C., 2006. Measuring Campaign Spending Effects in U.S. House Elections, in Capturing Campaign Effects, ed. H. Brady R. Johnston. Ann Arbor: University of Michigan Press.

Krasno, J.S., Green, D.P., 1988. Preempting Quality Challengers in House Elections. Journal of Politics 50, 920-36.

Levitt, S.D., 1994. Using Repeat Challengers to Estimate the Effect of Campaign Spending on Election Outcomes in the U.S. House. Journal of Political Economy 102(4), 777-798.

Milligan, K., Smart, M., 2006. Regionalism and Pork Barrel Politics. Working Paper.

Nagler, J., Leighley, J., 1992. Presidential Campaign Expenditures: Evidence on Allocations and Effects. Public Choice 73, 319-333. 
Palda, K.F., Palda, K.S., 1985. Ceilings on Campaign Spending: Hypothesis and Partial Test with Canadian Data. Public Choice 45, 313-331.

Palda, F., Palda, K., 1998. The Impact of Campaign Expenditures on Political Competition in the French Legislative Elections of 1993. Public Choice 94, 157-174.

The Province, 2007. "West Vancouver-Sunshine Coast MP has Unpaid Debts, Allegations of Improper Campaign Spending,” Sunday, October $29^{\text {th }}$, page 1.

Rekkas, M., 2007. The Impact of Campaign Spending on Votes in Multiparty Elections. Review of Economics and Statistics 89(3), 573-585.

Stratmann, T., Aparicio-Castillo, F.J., 2006. Competition Policy for Elections: Do Campaign Contribution Limits Matter? Public Choice 127, 177-206.

Welch, W.P., 1981. Money and Votes: A Simultaneous Equation Model. Public Choice 36, 209234. 
Table 1: Election expenditures by candidates in the 1997 and 2000 federal elections

\begin{tabular}{|c|c|c|c|c|c|c|c|c|}
\hline & \multicolumn{6}{|c|}{ percentiles } & \multirow[b]{2}{*}{ Mean } & \multirow[b]{2}{*}{ Std Dev. } \\
\hline & $\mathrm{N}$ & 10th & 25th & 50th & 75th & 90th & & \\
\hline All observations & 3480 & 0 & 731 & 12,106 & 45,812 & 59,680 & 22,807 & 23,788 \\
\hline 1997 only & 1672 & 0 & 1,317 & 18,336 & 47,250 & 59,157 & 24,713 & 23,241 \\
\hline 2000 only & 1808 & 0 & 508 & 7,274 & 43,997 & 60,051 & 21,044 & 24,156 \\
\hline Liberal & 602 & 29,213 & 40,349 & 51,158 & 59,592 & 64,563 & 48,761 & 14,327 \\
\hline PC & 592 & 994 & 5,724 & 18,195 & 39,204 & 55,271 & 23,487 & 19,913 \\
\hline Ref/CA & 525 & 2,141 & 12,598 & 31,925 & 50,175 & 61,543 & 31,775 & 21,436 \\
\hline NDP & 599 & 0 & 1,245 & 7,366 & 23,986 & 51,847 & 15,942 & 19,345 \\
\hline BQ & 150 & 23,930 & 50,968 & 59,427 & 64,900 & 70,531 & 54,486 & 16,514 \\
\hline Fringe & 1012 & 0 & 0 & 187 & 1,504 & 3,688 & 1,685 & 5,219 \\
\hline $\begin{array}{l}\text { Below median } \\
\text { population density }\end{array}$ & 1737 & 0 & 1,965 & 19,042 & 47,910 & 60,517 & 25,449 & 23,700 \\
\hline $\begin{array}{l}\text { Above median } \\
\text { population density }\end{array}$ & 1743 & 0 & 202 & 7,151 & 42,194 & 58,999 & 20,173 & 23,590 \\
\hline Incumbents & 526 & 36,406 & 44,993 & 54,009 & 60,681 & 65,704 & 52,520 & 11,342 \\
\hline challengers & 2954 & 0 & 344 & 6,114 & 32,198 & 55,007 & 17,516 & 24,414 \\
\hline Winners & 602 & 37,263 & 45,079 & 54,220 & 60,752 & 65,704 & 52,774 & 11,099 \\
\hline Losers & 2878 & 0 & 315 & 5,435 & 28,734 & 52,814 & 16,538 & 20,769 \\
\hline
\end{tabular}

Notes: Reported are the moments from the distribution of campaign expenses for different subsamples of the dataset. 
Table 2: The impact of expenditure limits on expenses

\begin{tabular}{|c|c|c|c|c|c|c|c|}
\hline & $\begin{array}{c}\text { Quartic } \\
\text { Formula } \\
\text { Controls }\end{array}$ & $\begin{array}{c}\text { Add Census } \\
\text { and Politica } \\
\text { Controls }\end{array}$ & & $\begin{array}{c}\text { Just } \\
\text { Major } \\
\text { Parties }\end{array}$ & & $\begin{array}{l}\text { Just } \\
\text { Incumbents }\end{array}$ & \\
\hline & (a) & (b) & & (c) & & (d) & \\
\hline Number of observations & 3480 & 3480 & & 2468 & & 526 & \\
\hline R-squared & 0.031 & 0.651 & & 0.508 & & 0.303 & \\
\hline Limit & $\begin{array}{c}0.04 \\
(0.10)\end{array}$ & $\begin{array}{c}0.07 \\
(0.09)\end{array}$ & & $\begin{array}{c}0.10 \\
(0.12)\end{array}$ & & $\begin{array}{c}0.42 \\
(0.18)\end{array}$ & ** \\
\hline Incumbent & -- & $\begin{array}{l}-2.86 \\
(1.22)\end{array}$ & $* *$ & $\begin{array}{l}-3.23 \\
(1.24)\end{array}$ & $* * *$ & -- & \\
\hline Progressive Conservative & -- & $\begin{array}{l}-16.71 \\
(1.14)\end{array}$ & $* * *$ & $\begin{array}{l}-17.35 \\
(1.14)\end{array}$ & $* * *$ & $\begin{array}{c}0.82 \\
(2.89)\end{array}$ & \\
\hline Reform / Canadian Alliance & -- & $\begin{array}{l}-11.93 \\
(1.13)\end{array}$ & $* * *$ & $\begin{array}{l}-12.61 \\
(1.15)\end{array}$ & $* * *$ & $\begin{array}{c}-0.09 \\
(2.54)\end{array}$ & \\
\hline New Democratic & -- & $\begin{array}{l}-24.08 \\
(1.13)\end{array}$ & $* * *$ & $\begin{array}{l}-24.72 \\
(1.13)\end{array}$ & $* * *$ & $\begin{array}{c}1.63 \\
(2.06)\end{array}$ & \\
\hline Bloc Quebecois & -- & $\begin{array}{l}10.65 \\
(1.36)\end{array}$ & $* * *$ & $\begin{array}{l}12.63 \\
(1.38)\end{array}$ & $* * *$ & $\begin{array}{c}7.31 \\
(1.94)\end{array}$ & *** \\
\hline Fringe & -- & $\begin{array}{l}-37.91 \\
(0.95)\end{array}$ & $* * *$ & -- & & $\begin{array}{l}-5.89 \\
(7.33)\end{array}$ & \\
\hline Past MP & -- & $\begin{array}{l}21.46 \\
(1.57)\end{array}$ & $* * *$ & $\begin{array}{l}21.41 \\
(1.59)\end{array}$ & $* * *$ & -- & \\
\hline Provincial experience & -- & $\begin{array}{c}3.99 \\
(1.74)\end{array}$ & $* *$ & $\begin{array}{c}4.23 \\
(1.80)\end{array}$ & $* *$ & $\begin{array}{c}1.09 \\
(1.70)\end{array}$ & \\
\hline Municipal experience & -- & $\begin{array}{l}-2.91 \\
(1.20)\end{array}$ & $* *$ & $\begin{array}{l}-3.81 \\
(1.20)\end{array}$ & $* * *$ & $\begin{array}{l}-0.37 \\
(1.05)\end{array}$ & \\
\hline Education & -- & $\begin{array}{l}-1.64 \\
(1.31)\end{array}$ & & $\begin{array}{l}-2.20 \\
(1.36)\end{array}$ & & $\begin{array}{c}1.62 \\
(1.13)\end{array}$ & \\
\hline
\end{tabular}

Table continued on next page. 


\section{Table 2 (Continued)}

\begin{tabular}{|c|c|c|c|c|c|c|c|}
\hline & $\begin{array}{c}\text { Quartic } \\
\text { Formula } \\
\text { Controls } \\
\text { (a) }\end{array}$ & $\begin{array}{l}\text { Add Census } \\
\text { and Political } \\
\text { Controls } \\
\text { (b) }\end{array}$ & & $\begin{array}{c}\begin{array}{c}\text { Just } \\
\text { Major } \\
\text { Parties }\end{array} \\
\text { (c) }\end{array}$ & & $\begin{array}{c}\begin{array}{c}\text { Just } \\
\text { Incumbents }\end{array} \\
\text { (d) }\end{array}$ & \\
\hline $\begin{array}{l}\text { Average income } \\
\text { (\$1000s) }\end{array}$ & -- & $\begin{array}{c}0.08 \\
(0.04)\end{array}$ & $* *$ & $\begin{array}{c}0.10 \\
(0.06)\end{array}$ & * & $\begin{array}{c}0.26 \\
(0.09)\end{array}$ & 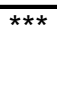 \\
\hline Primary sector share & -- & $\begin{array}{l}-27.85 \\
(7.86)\end{array}$ & $* * *$ & $\begin{array}{l}-30.19 \\
(10.01)\end{array}$ & $* * *$ & $\begin{array}{c}-63.94 \\
(15.55)\end{array}$ & *** \\
\hline Goods sector share & -- & $\begin{array}{l}-2.52 \\
(5.22)\end{array}$ & & $\begin{array}{l}-0.66 \\
(7.49)\end{array}$ & & $\begin{array}{l}-10.96 \\
(10.32)\end{array}$ & \\
\hline Primary education share & -- & $\begin{array}{l}11.61 \\
(8.48)\end{array}$ & & $\begin{array}{c}18.50 \\
(11.26)\end{array}$ & & $\begin{array}{l}59.39 \\
(18.10)\end{array}$ & 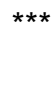 \\
\hline High School graduate share & -- & $\begin{array}{c}7.14 \\
(17.87)\end{array}$ & & $\begin{array}{l}15.39 \\
(23.74)\end{array}$ & & $\begin{array}{c}67.91 \\
(37.17)\end{array}$ & * \\
\hline $\begin{array}{l}\text { Some post-secondary } \\
\text { education share }\end{array}$ & -- & $\begin{array}{c}7.57 \\
(12.93)\end{array}$ & & $\begin{array}{l}-11.40 \\
(18.83)\end{array}$ & & $\begin{array}{l}-3.94 \\
(27.37)\end{array}$ & \\
\hline Age 15-44 share & -- & $\begin{array}{c}54.15 \\
(17.18)\end{array}$ & $* * *$ & $\begin{array}{l}90.73 \\
(23.02)\end{array}$ & $* * *$ & $\begin{array}{c}44.83 \\
(41.59)\end{array}$ & \\
\hline Age 45-64 share & -- & $\begin{array}{c}10.71 \\
(17.94)\end{array}$ & & $\begin{array}{l}23.06 \\
(23.54)\end{array}$ & & $\begin{array}{c}-38.01 \\
(37.70)\end{array}$ & \\
\hline Age 65 plus share & -- & $\begin{array}{c}53.63 \\
(15.91)\end{array}$ & $* * *$ & $\begin{array}{c}84.51 \\
(21.27)\end{array}$ & $* * *$ & $\begin{array}{c}74.62 \\
(36.09)\end{array}$ & ** \\
\hline Share of renters & -- & $\begin{array}{l}-2.51 \\
(8.81)\end{array}$ & & $\begin{array}{c}-1.87 \\
(11.88)\end{array}$ & & $\begin{array}{c}7.01 \\
(17.35)\end{array}$ & \\
\hline Immigrant share & -- & $\begin{array}{l}-1.87 \\
(3.60)\end{array}$ & & $\begin{array}{l}-7.16 \\
(4.81)\end{array}$ & & $\begin{array}{c}9.54 \\
(7.05)\end{array}$ & \\
\hline
\end{tabular}

Notes: Reported are the results from 4 separate regressions. Included in the specifications but not reported are provincial dumy varaibles, a year dummy variable, and a constant term. Columns (a) through (c) also include quartic terms in elector density and the number of electors. Standard errors are robust corrected. One, two, and three asterisks show statistical significance at the 10, 5, and 1 percent level respectively. 
Table 3: The Impact of Campaign Spending on Vote Shares, Pooled Sample

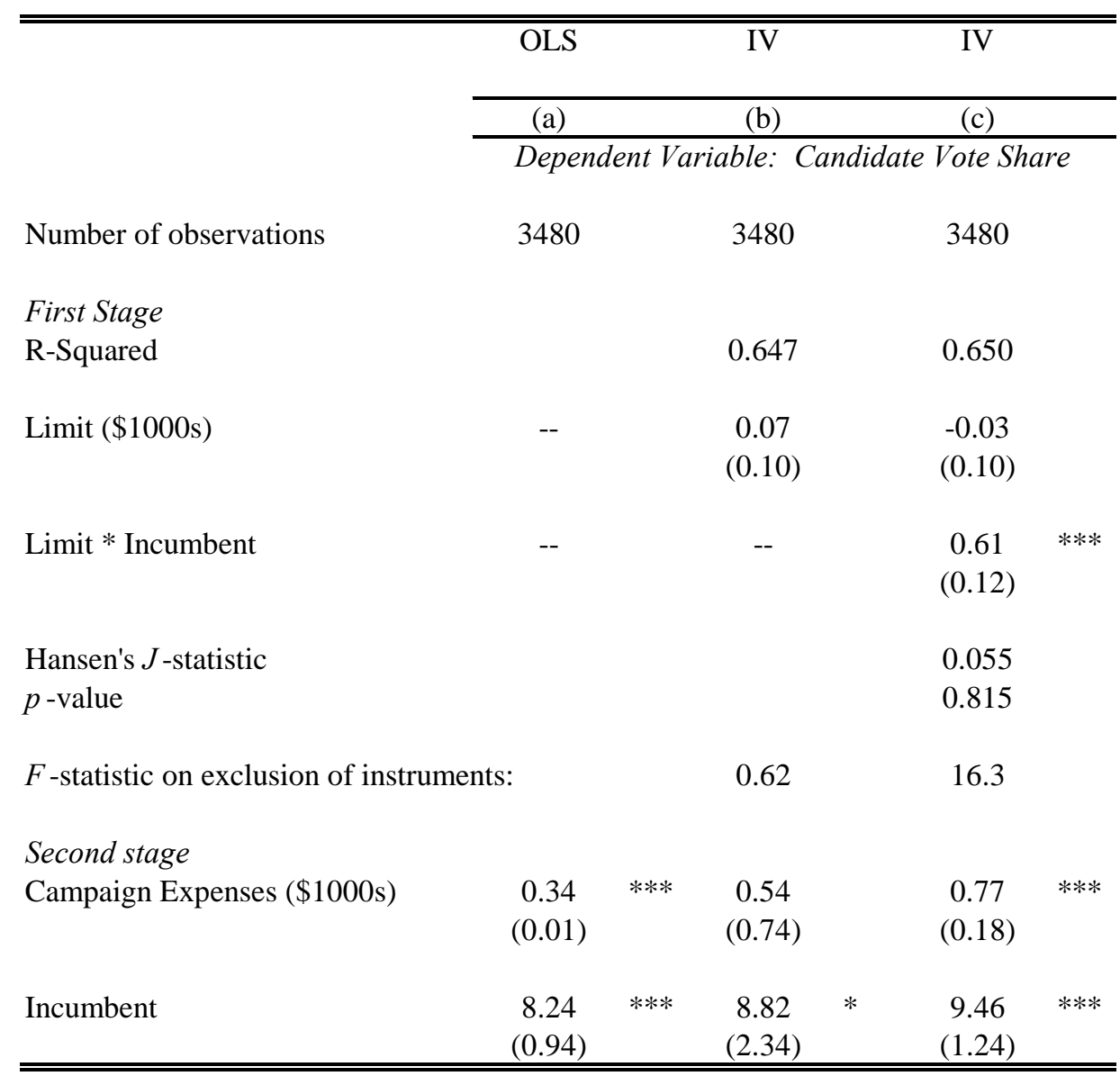

Notes: Reported are the regression coefficients from different regressions in each column. First stage coefficients are in the top panel and second stage coefficients are in the bottom panel. The specification includes all variables shown in Table 2 column (b). Standard errors are robust corrected. One, two, and three asterisks show statistical significance at the 10, 5, and 1 percent level respectively. 


\section{Table 4: The Impact of Campaign Spending on Vote Shares, Separate Samples}

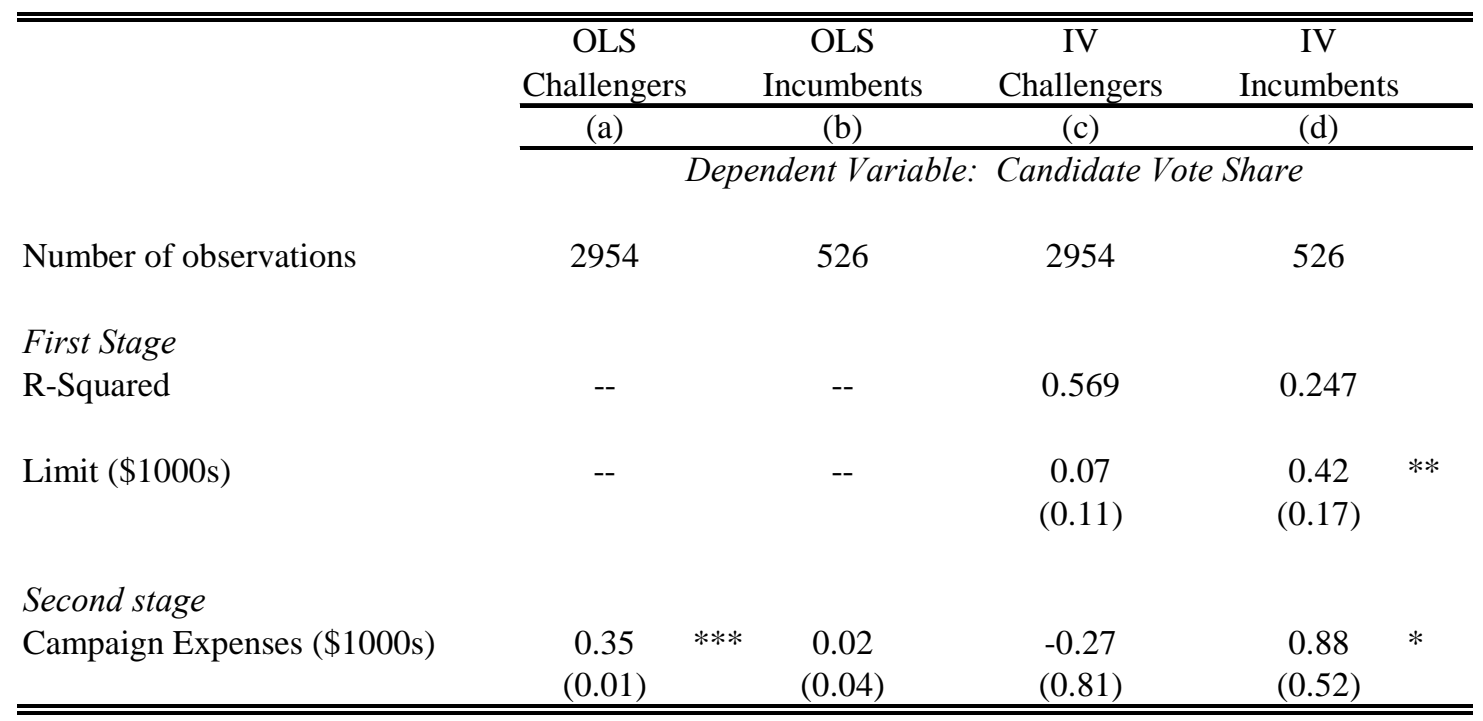

Notes: Reported are the regression coefficients from different regressions in each column. The specification includes all variables shown in Table 2 column (b). Standard errors are robust corrected. One, two, and three asterisks show statistical significance at the 10, 5, and 1 percent level respectively.

\section{Table 5: The Impact of Expenditure Limits on District-level Outcomes}

\begin{tabular}{|c|c|c|c|c|c|c|c|c|}
\hline Dependent Variable: & Margin & & $\begin{array}{l}\text { Voter } \\
\text { Turnout }\end{array}$ & & $\begin{array}{l}\text { Number of } \\
\text { Candidates }\end{array}$ & & $\begin{array}{c}\text { Incumbent } \\
\text { Victory }\end{array}$ & \\
\hline & (a) & & (b) & & (c) & & (d) & \\
\hline Number of observations & 602 & & 602 & & 602 & & 602 & \\
\hline Mean of Dependent Variable & 22.34 & & 64.03 & & 5.78 & & 0.769 & \\
\hline R-squared & 0.375 & & 0.722 & & 0.492 & & 0.144 & \\
\hline Limit (\$1000s) & $\begin{array}{c}0.831 \\
(0.217)\end{array}$ & *** & $\begin{array}{l}-0.266 \\
(0.056)\end{array}$ & *** & $\begin{array}{l}-0.046 \\
(0.019)\end{array}$ & $* *$ & $\begin{array}{c}0.003 \\
(0.001)\end{array}$ & $* *$ \\
\hline
\end{tabular}

Notes: Reported are the regression coefficients from different regressions in each column. The specification includes all variables shown in Table 2 column (b), but without party and incumbency controls. Standard errors are robust corrected. One, two, and three asterisks show statistical significance at the 10, 5, and 1 percent level respectively. 
Figure 1: Distribution of District-level spending limits

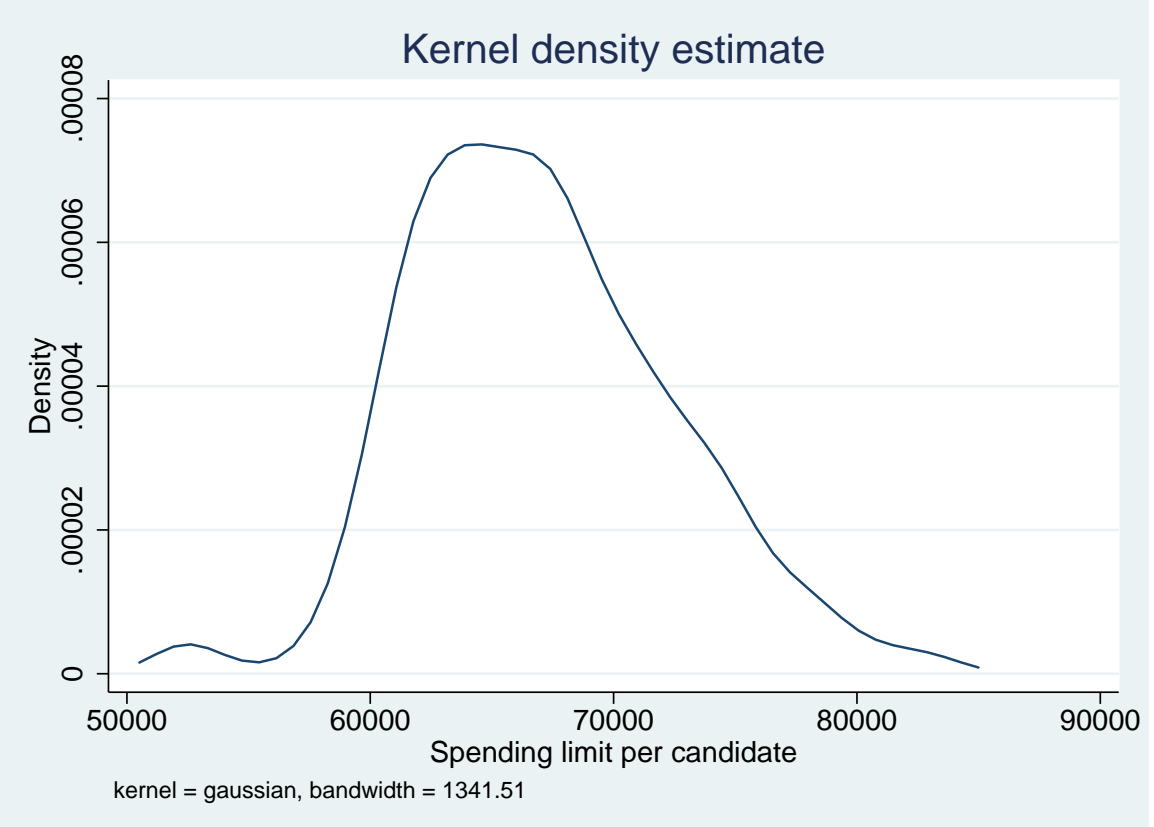

Notes: Kernel smoothed density using Gaussian kernel. Dollar values translated to 2000 dollars.

Figure 2: Limits and Electors per District

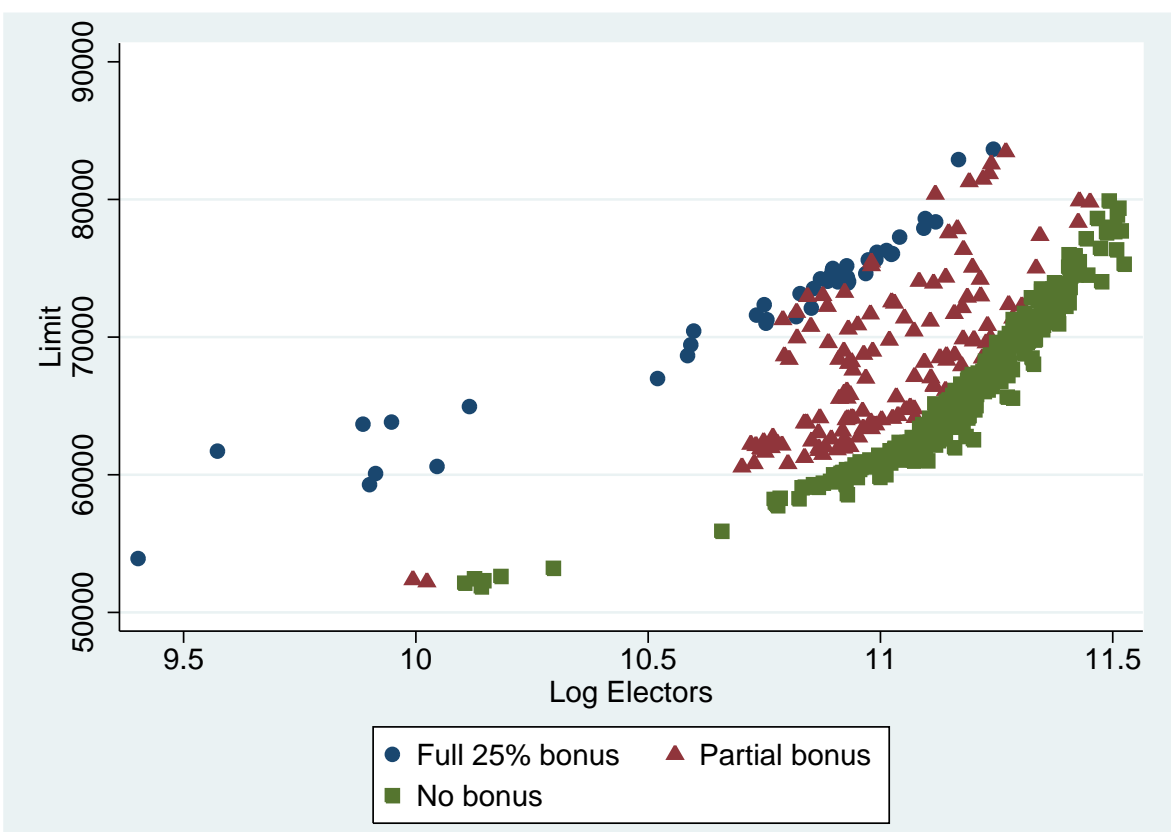

Notes: Each data point represents one district in one election year. Dollar values converted to 2000 dollars. 
Figure 3: Limits and Elector Density

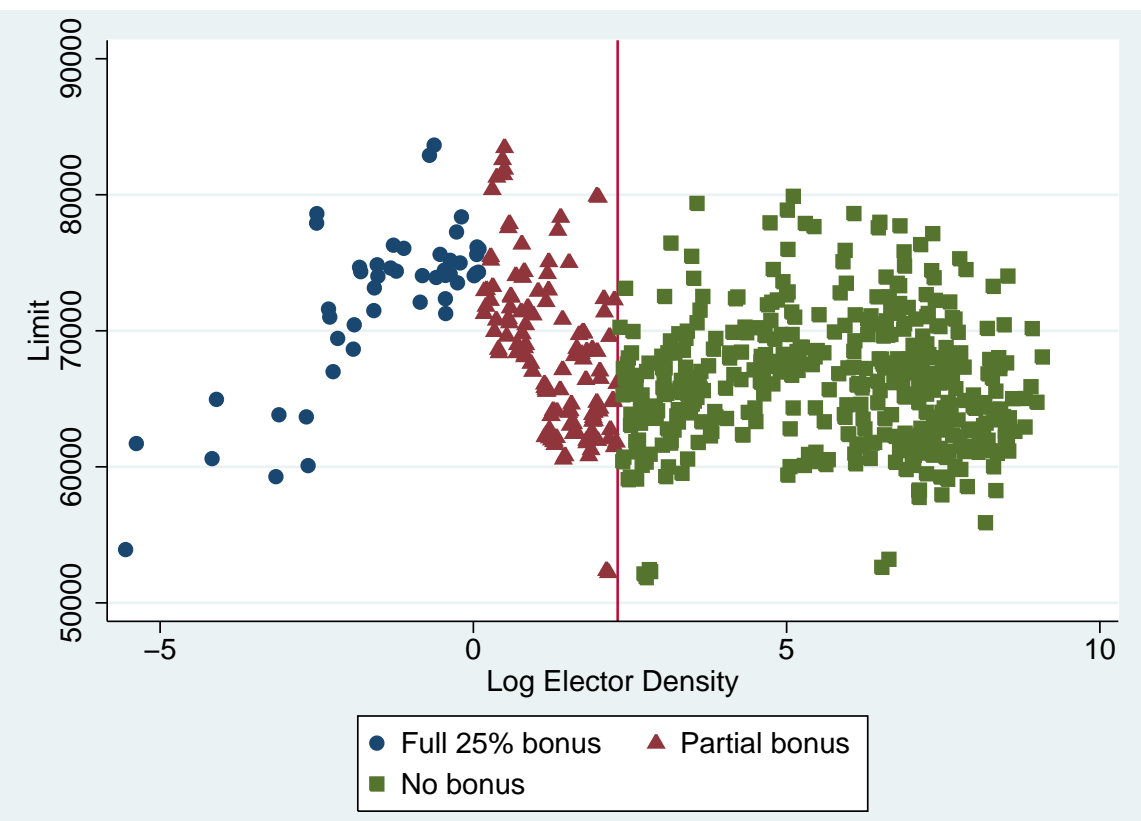

Notes: Each data point represents one district in one election year. Dollar values converted to 2000 dollars.

Figure 4: Distribution of campaign expenditures for all candidates

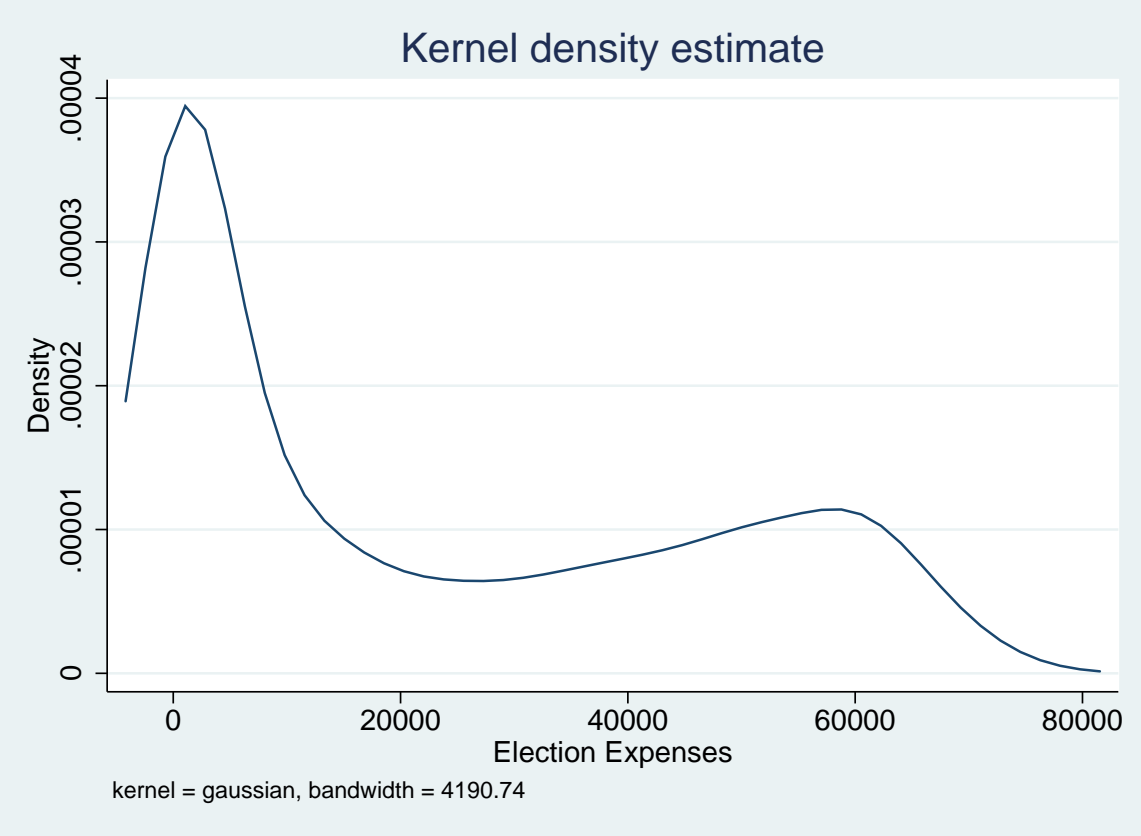

Notes: Kernel smoothed density using Gaussian kernel. Dollar values translated to 2000 dollars. Unit of observation is a candidate in a given election. 
Figure 5: Spending limits vs. vote shares for incumbent candidates

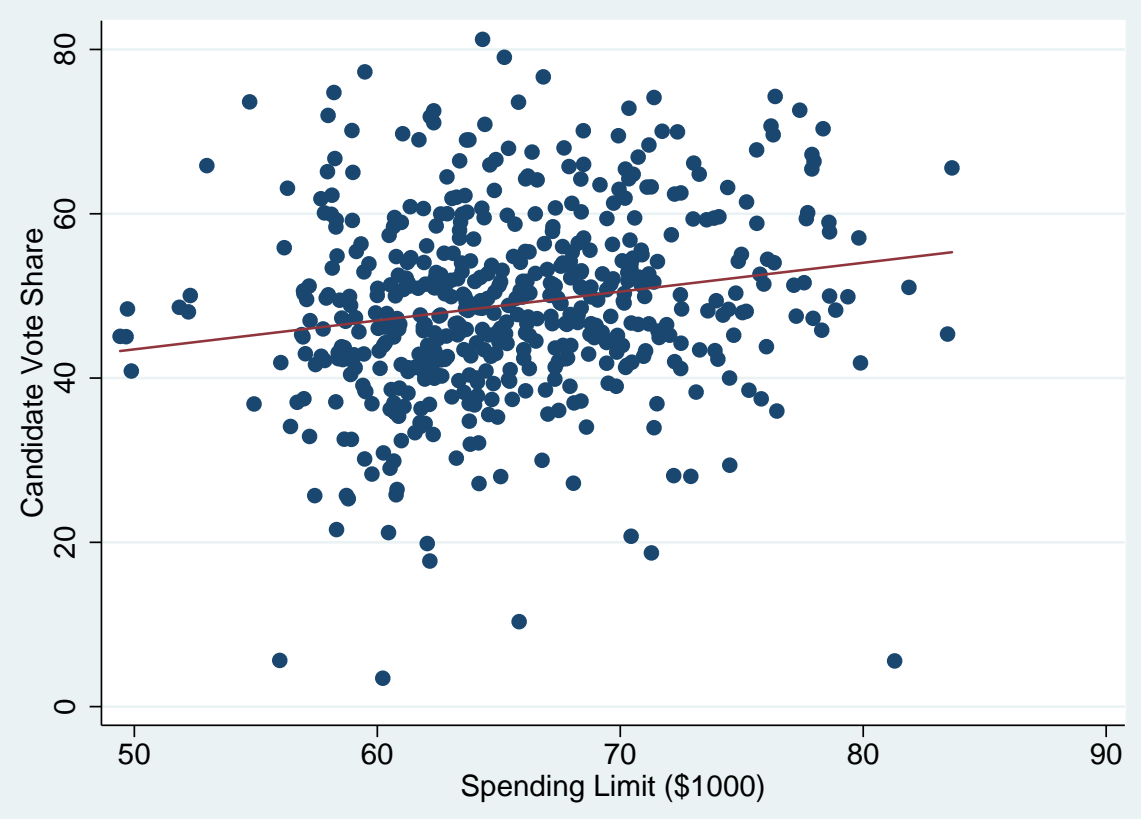

